University of South Florida

DIGITAL COMMONS

@ UNIVERSITY OF SOUTH FLORIDA
Digital Commons @ University of

South Florida

$1-1-2001$

\title{
National Center for Transit Research Promotional Materials Clearinghouse. Year IV Final Report
}

CUTR

Follow this and additional works at: https://digitalcommons.usf.edu/cutr_nctr

\section{Scholar Commons Citation}

CUTR, "National Center for Transit Research Promotional Materials Clearinghouse. Year IV Final Report" (2001). Research Reports. 207.

https://digitalcommons.usf.edu/cutr_nctr/207

This Technical Report is brought to you for free and open access by the National Center for Transit Research (NCTR) Archive (2000-2020) at Digital Commons @ University of South Florida. It has been accepted for inclusion in Research Reports by an authorized administrator of Digital Commons @ University of South Florida. For more information, please contact digitalcommons@usf.edu. 


\section{National Center for Transit Research Promotional Materials Clearinghouse Year IV Final Report}

Prepared by

The Marketing Institute

Florida State University College of Business

January 2001

For

National Center for Transit Research

University of South Florida 


\section{Table of Contents}

PROJ ECT BACKGROUND..................................................................1

Task 1: Continue Materials Acquisition ...............................................3

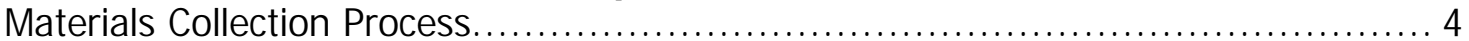

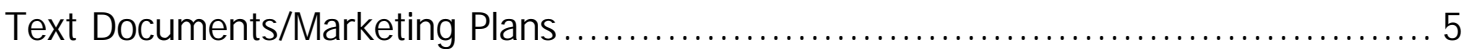

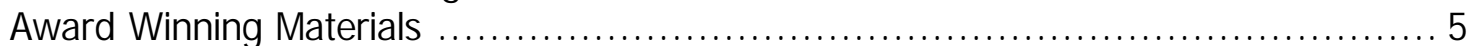

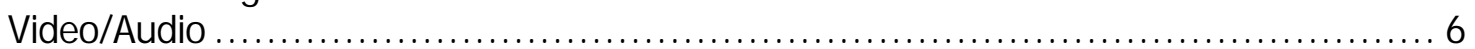

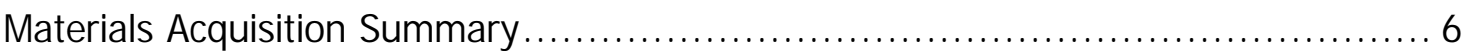

Task 2: I mprove I nformation Distribution Process ............................. 7

Browser Capabilities .................................................................. 7

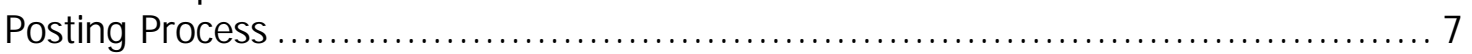

TASK 3: Evaluate current and Future needs of Public Transportation

Marketers ...........................................................................................8

TASK 4: Collection and Distribution of Award Winners .........................8

TASK 5: Technical Assistance .............................................................9

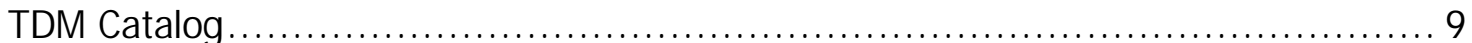

2000 ACT International Conference - Orlando, FL................................ 10

TASK 6: Final Report .......................................................................10

FUTURE NEEDS \& CONCLUDI NG REMARKS .......................................11

Appendix

ITEM A: Materials Submission Questionnaire

ITEM B: Preliminary Draft Needs Assessment Survey

ITEM C: "TDM Marketing: Creating a Visual I dentity" 


\section{PROJ ECT BACKGROUND}

Development of promotional and communications collateral can be an expensive and timeconsuming undertaking for public transit systems, especially in today's environment of down-sizing and tight budgeting. An unfortunate consequence of such downsizing is the toll it takes on the marketing efforts of transit systems and TDM agencies whose marketing budgets are often required to do more with less.

A survey of transportation professionals conducted by the Marketing Institute at Florida State University's College of Business in 1995 revealed that one possible solution to this dilemma was the creation of a transit marketing clearinghouse. Ideally, this clearinghouse would archive marketing collateral from transit systems throughout the U.S. and provide transit marketers with on-demand access to this information. It was believed that such an exchange would help reduce the budget and time demands associated with the production of new promotional materials and promote enhanced communication between transit marketers.

Additional considerations focused on the communications medium best equipped to achieve the goals of such a project. The adopted medium would not only facilitate the exchange of information but would also reflect the changing nature of information gathering and distribution in the marketplace.

In the end, the Internet, primarily the World Wide Web (WWW), showed the most promise in bringing the clearinghouse concept to fruition. It was envisioned that users would access a designated web site and review examples of transit marketing collateral froma round the nation. Furthermore, when permitted users would be able to download artowkr which could then be incorporated into the design of their own marketing and promotional collateral.

When a proven ability to fuse the talents of faculty, staff and students at Florida State University's College of Business, the Marketing Institute (then the Florida Institute for Marketing Alternative Transportation) sought funding to initiate the project. The requested funding was granted by the U.S. DOT's National Urban Transit Institute, and in 1996, the project became a reality.

Since that time the Clearinghouse has evolved in accordance with trends in public transit services and the field of marketing. Furthermore, the inclusion of transportation demand management (TDM) interests to the Clearinghouse has also greatly enhanced and broadened the benefit of the project. And in 2000, the operational year for which this report is being written, the National Urban Transit Institute became the National Center for Transit Research (NCTR), and the Clearinghouse now operates under the auspices of that organization.

The information that follows provides a summary of the activities undertaken in the project's most current year of operation. This report also summarizes the tasks originally identified in the project proposal and the actions taken towards their completion. Any alterations to the plan, as have already been addressed in the quarterly progress reports submitted to the Center for Urban Transportation Research, are also identified here. 
This report does not represent the product itself. Instead, the web site and its associated materials are available for review online at http://nuti.cob.fsu.edu. For documentation purposes, the site and other relevant documents referenced in this report have been burned onto the attached CD ROM and reflect the site as of January 2001. (Please refer to accompanying documentation for file retrieval instructions.) This report is rather a summation of the actions that have lead to the current incarnation of the Clearinghouse web site and its associated technical support and instructional activities. 


\section{Task 1: Continue Materials Acquisition}

Initiation of the Promotional Materials Clearinghouse was predicated on the need for a forum through which transit marketers could view the work of their peers in a variety of different markets. Subsequently, the primary focus of the Clearinghouse has been the acquisition and posting of marketing collateral from transit systems from both the U.S. and Canada.

During this most recent operational year, TDM agencies were contacted more frequently as a resource for promotional collateral. Whereas in years past, the primary focus had been transit materials, it has been discovered that TDM agencies not only have a lot to gain from the Clearinghouse, they also have substantial materials and expertise to contribute.

Materials customarily solicited from these agencies include brochures, posters, print advertising, and direct mail advertising. More effort, however, was put into collecting these materials as they relate to broader promotional efforts by the sponsoring agency. For example, although informational brochures that simply summarized the provisions of particular service programs such as Guaranteed Ride Home Programs were solicited, more focused efforts went into collecting materials that promoted the agency and their services in a competitive environment.

This "competitive environment" was used to define a market situation in which transit systems were competing with other entities for the limited attention of consumers. Various non-profit and for-profit groups utilized print advertising, direct mail, etc. as a means to garnering a large share of the consumer market. Transit's ability to compete in this arena has been of great interest to transit marketers for years. Therefore, examples of print advertising, billboards, direct mail, and other promotional literature were the focus of most acquisition efforts. (Refer to Figures 1 and 2 for examples of informational vs. promotional literature.)
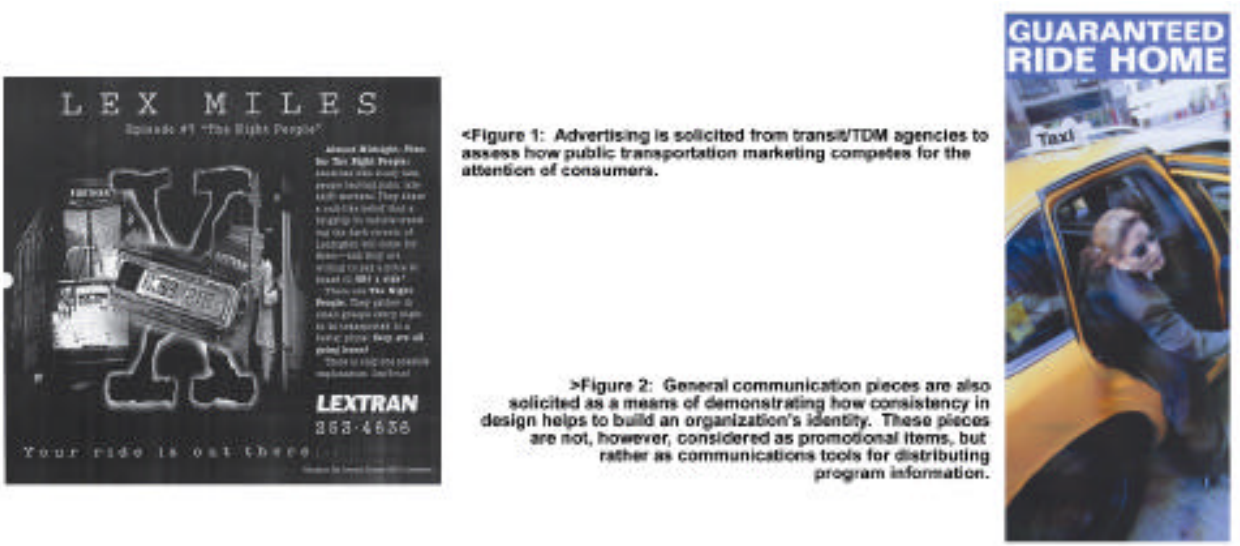

The Clearinghouse did not, however, exclude the collection of information brochures and other materials. These materials are a very important component of a transit system or TDM agency's communications efforts. Without such materials, a vital communication link between transit and TDM agencies and their customers is missing. 
Unfortunately, in the midst of junk-mail frenzies that consumers endure every day, brochures that promote transit or TDM services get lost. Subsequently, the Clearinghouse was intent on acquiring materials that were innovative in both their design and delivery. For this reason, collection of these materials was conducted using awards programs as the primary acquisition avenue. (See "Award Winning Materials" for information on this topic.)

\section{Materials Collection Process}

During the Clearinghouse's first year of operation, forty-three transit systems contributed materials to the project. Furthermore, through our acquisition process, the Marketing Institute was added to the mailing lists of a variety of both transit and TDM agencies. Consequently, the bulk of materials received via this process were newsletters, service brochures, and annual/quarterly reports.

The acquisition of more specialized promotional materials were undertaken either through awards programs by both the Association for Commuter Transportation (ACT) or the American Public Transit Association (APTA) or through solicitation letters. This latter process was typically initiated upon review of periodicals published by both the aforementioned organizations. Passenger Transport, the monthly publication of APTA, and TDM Review, the quarterly publication of ACT, were routinely reviewed to identify promotional and marketing campaigns of interest to the Clearinghouse. Once identified, solicitation letters were submitted to the appropriate agency requesting additional information about the program and any associated promotional literature.

Following the acquisition process, questionnaires were forwarded to the submitting agency asking them basic information about the particular piece(s). The information gathered from these questionnaires was then used to develop a narrative to accompany the piece once it was posted on the Clearinghouse web site. (This questionnaire is included in the Appendix as Item A).

In all circumstances during this operating year, materials submitted to the Clearinghouse were in the final printed form (with the exception of video and audio). Despite requests to have materials submitted in digital format, most agencies simply submitted materials as they were distributed to the general public. A preference for digital versions of the artwork arose from concerns about time and turnaround. Without the digital version, Clearinghouse staff simply scanned the materials for posting.

To ease navigation through the extensive collection of materials, materials are categorized into one of eight sub-categories. These categories include niche marketing, advertising, annual reports, direct mail, employer marketing, rideshare marketing, "how to ride" guides, and special promotions. A category was also added to include video, but video and audio are discussed in a later section of this report. 


\section{Text Documents/ Marketing Plans}

A parallel task of the materials acquisition process was solicitation for and receipt of textbased documents. Although strategic marketing plans were at the cornerstone of this solicitation activity, attempts were also made to gather materials that would function as instructional or "how-to" documents.

At the end of the Clearinghouse's third year of operation, a new section of the web site was added entitled "Imagine." Here, users could access instructional information on developing and distributing marketing materials at substantially reduced cost. Individuals within the TDM and transit industry were also asked to submit these instructional texts.

The desire to contact these individuals typically arose from exposure to their work at national and regional conferences and workshops. For example, Ms. Deana Faun of the Mid-America Planning Council in Kansas City was asked to submit an instructional document on newsletter marketing following a presentation at the 2000 ACT International Conference. Ms. Margaret Giery of the University of South Florida was asked to contribute materials on events marketing per the same conference.

Both Ms. Dean and Ms. Giery have agreed to work in cooperation with the Marketing Institute to develop and post these materials. Development and posting of these documents is still in process, and they have not been posted as of this writing. They do, however, represent the types of materials on which Institute staff focused during the past year with regards to print documents.

\section{Award Winning Materials}

Not all materials submitted to the Clearinghouse were posted. Instead, representative samples of materials were posted that illustrated effective uses of marketing strategy or information design/distribution. Furthermore, Clearinghouse staff undertook efforts to showcase the best of the best. Consequently, award-winning materials as deemed so by either APTA or ACT have become a cornerstone of the collection process.

Each year, APTA presents its AdWheel awards to transit systems who excel in their marketing and communications efforts. The Marketing Institute has built a cooperative relationship with APTA over the past few years in order to more readily acquire these materials for posting on the Clearinghouse web site. Subsequently, in the Fall of 2000, request letters were sent to all recipients of a 2000 AdWheel award. Of the eighty (80) solicitation letters sent, approximately forty-five (45) transit systems submitted materials to the Clearinghouse.

ACT also recognizes excellence in marketing during its annual international conference. However, due to the Marketing Institute's close working relationship with the ACT Awards Committee, materials were simply forwarded to the Clearinghouse once winners had been announced. 


\section{Video/ Audio}

Video features were added to the Clearinghouse during 2000. Despite attempts in the past to post such information, limited bandwidth capabilities by some users made the efficient delivery of video online quite difficult. Fortunately, since that time, readily-available ISDN, DSL, and cable-modem connections have reduced accessibility concerns.

Video on the Clearinghouse is available in attentive to the bandwidth issues some users might still encounter. High-res and low-res Quicktime movies are posted on the Clearinghouse as an added benefit to users.

\section{Materials Acquisition Summary}

The following achievements were highlights of the materials acquisition process during the duration of this project.

- Approximately 70 materials were added to the gallery as a result of solicitation of both transit and TDM agencies.

- Both APTA and ACT worked cooperatively with the Marketing Institute to highlight achievements in transit and TDM marketing.

- APTA and ACT provided access to membership listings and winners of their respective annual awards programs.

- Video features were added to the Clearinghouse.

- A direct-mail showcase was added to the Clearinghouse gallery.

- Instructional materials were solicited from TDM professionals as a means of expanding the educational benefits of the Clearinghouse. 


\section{Task 2: I mprove Information Distribution Process}

As of this writing, the Promotional Materials Clearinghouse web site has undergone five adaptations. Each adaptation was undertaken to capitalize on new browsers capabilities and improving user navigation.

The Clearinghouse is comprised of four primary departments. The "Gallery" contains samples of promotional collateral from approximately fifty (50) transit systems. The "Gallery" is subsequently divided into nine (9) sub-categories as described in the previous section.

The section "Text" contains text-based documents including marketing plans, current transit statistics, and articles on the nature of marketing. "Links" is a listing of sources on the World Wide Web of specific interest and value to transit and TDM marketers. And "Imagine" is a recent addition that provides instructional support to the design and development of low-cost marketing materials.

Each of these sections was designed to be self-contained through a series of HTML frames. This self-containment provides greater navigational ease through the expansive amount of information. Appropriate links to other sections or documents within the site are included for cross-reference purposes.

A task that the Institute had hoped to incorporate into the Clearinghouse during 2000 was a search engine that would allow users search available materials by keywords. Unfortunately, initial trials with this procedure resulted in inefficient results. Therefore, a more comprehensive approach to the search process, incorporating ASP and database interactivity is currently in the early stages of re-development.

\section{Browser Capabilities}

An issue at the forefront of all design issues related to web sites is the capability of the end user, primarily their browser capabilities. The speed and conditions under which users can access information should always guide the design process and the quality of materials available for download. When the Clearinghouse first began operation in June 1996, the adopted guideline for posting of information on the web site was that most users would be using modems with an average access speed of 14.4 bps using traditional modem and phone lines. Now, due to growth in PC technology and information transfer rates, the standard has been adopted as follows: Most users will be using $4^{\text {th }}$ generation browsers with at least a $58 \mathrm{~K}$ modem.

\section{Posting Process}

The procedure for posting materials is impacted by numerous factors including staff availability and volume of incoming materials. The primary method for information delivery and materials exchange for the project is the Clearinghouse web site, accessible at http://nuti.cob.fsu.edu. The benefits of web usage are numerous including 24-hour daily access, easy adaptability to the changing needs of users, and immediate posting of timesensitive materials. 
Once received, materials for the Clearinghouse are catalogued for either the "Text" or "Gallery" sections of the web site. Further categorization of materials in the "Gallery" is then undertaken as described in the earlier section. Since the collection and sharing of marketing materials was the motivating force by the development of the Clearinghouse, most materials are by default categorized for the "Gallery."

All materials presented in the "Gallery" are prefaced by a thumbnail image of the collateral piece as well as a brief description of the piece's intended audience and use. By clicking on the thumbnail image, the user is presented with the larger composite image(s) of the collateral piece. The larger images often represent a compromise between detail and file size. To accommodate users with slower Internet connections, files are kept intentionally small (preferably $40 \mathrm{~K}$ or smaller) to facilitate quicker download time. In some cases, resolutions of images this small lose subtle detailing and the screen image becomes illegible and of little use to the viewer.

To address this problem, composite images were constructed which incorporated these essential elements of the collateral piece being viewed. Non-essential components such as mailing panels or repetitive design elements were removed from the final scanned image. What resulted was a representative image that included as much information as deemed necessary. Another approach to this problem has been the conversion of files into Adobe Acrobat PDFs which provide cross-platform viewing of documents in their entirety. Unfortunately, most documents are not submitted in either their digital form or as PDF. Without an original digital file from which to work, use of PDFs is limited to text documents at this time.

\section{TASK 3: Evaluate current and Future needs of Public Transportation Marketers}

Following four years of operation, Clearinghouse staff determined that it was appropriate to develop and implement a survey of transit and TDM marketers to assess the continued usefulness of the project. Results of this survey would allow Clearinghouse staff to adapt web site features that are responsive to the educational needs of users.

Unfortunately, due to delays in the original execution of this year's contract, the development and implementation of this survey has been postponed until the Spring of 2001. It is listed as Task 3 in Subagreement 2117-416-LO-A between the University of South Florida and Florida State University.

A preliminary draft of the needs assessment survey has been developed. However, it still requires review by Institute staff, CUTR, and the FSU Marketing Department. A copy of the preliminary survey is included as Item B in the Appendix.

\section{TASK 4: Collection and Distribution of Award Winners}

APTA's Annual AdWheel Competition highlights the best work of transit marketers throughout the U.S. and Canada. AdWheels are awarded in a variety of categories in one 
of five classifications: business member, government, small transit system, medium-sized transit system, and large transit system.

In the fall of 2000, APTA provided the Institute with a listing of all winners and submittals for the 2000 AdWheel Competition. Solicitation letters were subsequently sent to approximately fifty (50) transit systems. Thirty (30) systems responded by submitting materials to the Cle aringhouse which have since been posted.

Also, due to the Clearinghouse's developing interest in the work of ridesharing agencies throughout the country, Clearinghouse staff collected award winning materials and program information from ACT during this same time period. All entries in ACT's 2000 Awards Competition were submitted to the Institute following the ACT International Conference in Orlando. When applicable to the aims and goals of the Clearinghouse, these materials have been posted.

\section{TASK 5: Technical Assistance}

One of the truly rewarding and beneficial aspects of the Clearinghouse is the ability to provide instructional and technical support to transit and TDM marketers on issues of design as they pertain to branding and imaging.

The "Imagine" component of the Clearinghouse web site was developed specifically to support the needs of transit and TDM professionals. This component of the web site provides tutorial information on methods for reducing print and distribution costs. The site also contains a listing of other resources from which users can gather information on the availability and pricing of stock images. Additional links were research and posted that provide access to a variety of low-cost or free design resources of which transit marketers can take advantage.

During the past year, Clearinghouse staff was also available to help TDM and transit professional locate additional resources for use in their print and electronic media materials.

In addition to this operational component of the web site, Clearinghouse Project Manager Jeff Horton was involved in two instructional efforts involving wide-ranging interests and needs. These two activities included the compilation and distribution of a TDM marketing materials catalog and a presentation at the 2000 ACT International Conference.

\section{TDM Catalog}

In the summer of 2000, the Marketing Institute in cooperation with the Florida Department of Transportation and the Center for Urban Transportation Research (CUTR) at the University of South Florida, began the creation of a marketing materials catalog for use by Florida's TDM and transit properties.

The intent of this catalog was to provide Florida public transportation professionals with an overview of current promotional programs throughout the U.S. and Canada. Following an 
exhaustive solicitation process, the Institute was able to catalog approximately 80 promotional programs/actions.

The Clearinghouse served as the final repository for all the materials collected for the Catalog project. Furthermore, materials for the catalog were taken from Clearinghouse archives, providing greater variety in the scope and quality of materials available for review. Clearinghouse staff was also available to provide technical expertise and support to Florida's TDM and transit professionals in the use and adaptability of Catalog materials for use within their market. (A copy of the catalog is available as a PDF on the enclosed CD ROM.)

\section{ACT I nternational Conference - Orlando, FL}

Clearinghouse Manager Horton conducted a presentation at the 2000 ACT International Conference in Orlando, Florida, in October regarding the development of a consistent imaging system for TDM and transit systems. Approximately one hundred (100) representatives from the U.S., Canada, and Europe were in attendance at this presentation.

The Clearinghouse was used as a foundation for this presentation. Samples were drawn from the Clearinghouse archives to illustrate how good design can work for an organization while bad design may actually constraint an organization's growth and visibility. "TDM Marketing: Creating a Visual Identity" was a companion booklet that was developed for session attendees. A printed copy of this document is included as Item $\mathrm{C}$ in the Appendix while a PDF copy is included on the enclosed CD ROM.

\section{TASK 6: Final Report}

This document serves as completion of this task. 


\title{
FUTURE NEEDS \& CONCLUDI NG REMARKS
}

The Promotional Materials Clearinghouse continues to generate significant awareness from transit systems and TDM agencies throughout the U.S. As the Clearinghouse has evolved, however, greater interest has been witnessed in the technical support and instructional aspects of the project. Both the TDM Catalog and ACT International Conference, as discussed earlier in this report, have demonstrated a great need for the Clearinghouse's technical and design expertise. For this reason, as the Clearinghouse continues, more emphasis should be placed on the need for routine instruction in the areas of design, cost, distribution, and technology.

Since it's inception, the Clearinghouse web site has received in excess of 7000 hits. It has also generated correspondence from transportation professionals not only in the U.S. but in Europe and Asia. These requests demonstrate the value of the services offered by the Clearinghouse and the necessity for integrating marketing strategies into the development and maintenance of public transportation services.

However, to maintain relevance in the TDM and transit communities, the Clearinghouse will need to grow with the ever-changing needs of its users. As summarized earlier in this report, improvements to the project that would greatly benefit users include searchable databases, greater instructional support, and availability of ready-to-use templates for newsletters and brochures.

Requests for information about the Promotional Materials Clearinghouse and this report should be directed to:

\author{
the Marketing Institute \\ attn: Jeff Horton \\ Florida State University College of Business \\ 321 Rovetta Business Building \\ Tallahassee, FL 32306-1111 \\ (850) 644-2509 \\ fax (850) 644-6231 \\ $\underline{\text { http://tmi.cob.fsu.edu }}$
}




\section{APPENDIX}


ITEM A: Materials Submission Questionnaire 
Org. Name:

Phone \#:

Contact:

Theme/Campaign:

1) What was your target market?

2) What kind of piece is it? (i.e. direct mail, radio, T.V....)

3) What were the production costs? [This can include artist time, photographer, printing, production, and air time.]

4) What is it produced in-house?

If not, who did it? Name of firm:

Contact:

Phone:

5) Would you consider the campaign a success?

If so, how did you measure it?

6) What are the copyright or trademark restrictions for use of the piece by other TDM and transit agencies?

7) Were there any royalty costs involved in the use of artwork or photographs? 
ITEM B: Preliminary Draft - Needs Assessment Survey 


\section{Needs Assessment (Preliminary Draft) TDM and Public Transit Marketers}

[survey will ultimately be online.]

This survey is being conducted by the National Center for Transit Research's Promotional Materials Clearinghouse at the Marketing Institute at Florida State University's College of Business. The purpose of this survey to assess the marketing and promotional needs of transit and TDM marketers.

Name:

Title: [preferably this will be a drop-down menu]

Organization:

City: State:

What is the size (i.e. population) of your particular market?

If you are a transit marketer, what is the size of your current operating fleet (excluding demand-response vehicles)? vehicles

If you are a rideshare marketer, what is the current size of your client/ridematch database?

What is your current annual marketing budget? \$

Do you currently operate from a strategic marketing plan? $\mathrm{Y} N$

If yes, how often is this plan updated or amended?

Which of the following do you typically utilize for marketing and promotional purposes? (Please check all that apply.)

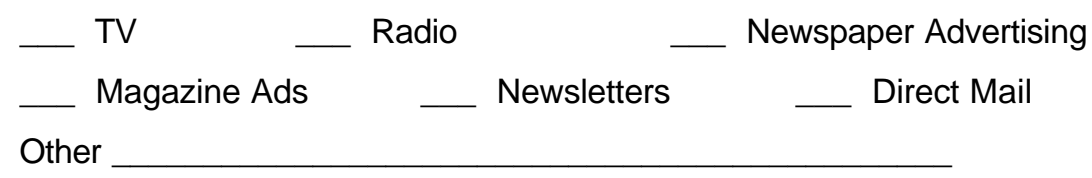

Of these, what promotional tools would you like to employ but can't due to current budgetary constraints?

In the past five years, have transit ridership or ridematch requests increased or decreased? Increased

Decreased 
What services provided by either FTA, APTA, ACT or other educational institutions would be of benefit to you as a marketer?

Access to a library of plug-n-play video and audio

Basic marketing workshops

Access to a catalog of marketing plans

Workshops that provide instructional support in the development and design of visual marketing tools

[more]

Online tutorials for design and cost-cutting issues

Were you aware of the Promotional Materials Clearinghouse prior to this survey? $\mathrm{Y} N$

Will you be more likely or less likely to access the Clearinghouse in the future?

More likely __ Less likely __ N No Change

Upon review of the Clearinghouse web site, please list any additional resources that could be added or improved that could benefit you as a marketer:

Would you be willing to contribute materials to the Clearinghouse for others to review? $\mathrm{Y}$ $\mathrm{N}$ 
ITEM C: “TDM Marketing: Creating a Visual I dentity" 